\title{
Pharmacological treatment of asthma today
}

\author{
K.F. Rabe, D.T. Schmidt
}

\begin{abstract}
Pharmacological treatment of asthma today. K.F. Rabe, D.T. Schmidt. (CERS Journals Ltd 2001.

ABSTRACT: The current concept of asthma therapy is based on a stepwise approach, depending on disease severity, and the aim is to reduce the symptoms that result from airway obstruction and inflammation, to prevent exacerbations and to maintain normal lung function.

$\beta_{2}$-Adrenoceptor agonists and glucocorticoids are at present the most effective drugs for the treatment of airway obstruction and inflammation, with theophylline, leukotriene receptor antagonists and anticholinergics as second- or third-line therapy. There are, to date, no additional or newly developed drugs available that add substantially to the current strategies or even replace $\beta_{2}$-adrenoceptor agonists or glucocorticoids. New approaches in asthma therapy recommend drug combinations of inhaled steroids, primarily with long-acting $\beta_{2}$-adrenoceptor agonists, based on their improved efficacy and the potential for a steroid-sparing effect.

Although existing drug entities are able to control the vast majority of patients with mild and moderate asthma, patients' (and doctors') adherence to guidelines and treatment strategies falls well short of the desired standards.

Treatment choices, however, differ between countries and should take into account convenience to the patient and the occurrence of side-effects. Additionally, the cost of therapy and reimbursement policies also influences therapeutic strategies.

Eur Respir J 2001; 18: Suppl. 34, 34s-40s.
\end{abstract}

\author{
Leiden University Medical Centre, \\ Dept of Pulmonology, Leiden, the \\ Netherlands. \\ Correspondence: K.F. Rabe \\ Leiden University Medical Centre \\ Dept of Pulmonology \\ C3-P \\ P.O. Box 9600 NL-2300 RC Leiden \\ The Netherlands \\ Fax: 31715266927
}

Keywords: Asthma

$\beta_{2}$-agonist

corticosteroids

leukotriene antagonists

pharmacology

Received: June 142001

Accepted June 202001
Bronchial asthma is an inflammatory disease of the airways, characterized by bronchial hyperresponsiveness and variable airway obstruction. Current pharmacotherapy aims primarily at symptomatic improvement through the use of bronchodilators and suppression of airway inflammation and decrease of bronchial hyperresponsiveness through the use of anti-inflammatory therapy.

The goal of the current and established treatment of asthma is minimization of symptoms, maintenance of normal lung function and prevention of irreversible changes within the airways. In future, it will be important to develop preventive and, possibly, curative therapeutic approaches, which are based on an improved understanding of the pathogenesis and pathophysiology of asthma.

Current treatment strategies advocate a stepwise approach to treatment, which depends on the severity of the disease [1]. This classification requires a standardized clinical assessment as well as measurement of lung function. Current pharmacotherapy should provide adequate control for the majority of patients; however, implementation of current guidelines, including lung function measurement and rational therapy, still falls well short of the desired standards [2].

\section{General considerations}

Asthma symptoms are mainly caused by recurrent episodes of acute airway narrowing that are believed to result from airway hyperresponsiveness and inflammation irrespective of whether the origin of the disease is allergic or nonallergic. The underlying mechanisms of airway hyperresponsiveness are still far from being completely understood.

In allergic asthma, it is assumed that the early-phase reaction is based on an immunoglobulin (Ig)-E mediated reaction with antigen cross-linking of Ig-E molecules bound to specific receptors on mast cells. Subsequent activation of Ig-E (FceRI receptors) leads to the release of bronchoconstricting mediators including leukotrienes and histamine. In contrast, the allergic late-phase reaction is believed to result from infiltration of the airway wall by inflammatory cells such as eosinophils and lymphocytes, especially CD4-positive T-cells. The mediators, which are released by these cells, are implicated in not only causing bronchoconstriction but also increasing bronchial responsiveness after allergen exposure. Repeated allergen exposure might lead to chronic changes within the airways and the well-described pathological aspects of airways from asthmatic patients, i.e. epithelial damage, hyperplasia of mucous glands, subepithelial fibrosis, collagen deposition, inflammatory cell infiltrates and increase in smooth muscle mass through hyperplasia and hypertrophy.

To date, asthma severity has been classified according to the frequency of symptoms in combination with lung function parameters such as forced expiratory volume in one second and peak expiratory 
flow; this classification forms the basis of a stepwise approach to asthma therapy. Although parameters that are assumed to reflect changes in airway inflammation have been used successfully to characterize patients and evaluate therapeutic effects within clinical studies, these parameters have not been taken into account in the current guidelines for the treatment of asthma. These indicators of airway inflammation, believed to be directly involved in the pathophysiology of asthma, are inflammatory cells (eosinophils, lymphocytes and mast cells) in induced sputum and bronchoalveolar lavage (BAL) fluid, inflammatory mediators (cytokines, chemokines, immunoglobulins, leukotrienes and prostanoids) in serum, urine, sputum and BAL fluid, and tissues obtained from the airways via biopsy (structure, adhesion molecules and receptors). Improved understanding of the relationship between symptoms on the one hand, and lung function and inflammatory parameters on the other, forms the basis of new concepts and approaches in the treatment of asthma.

\section{Established therapy and its further development}

The established treatment of asthma primarily comprises two classes of drug, bronchodilators and anti-inflammatory/immunosuppressive drugs. By far the most effective bronchodilators in asthma are $\beta_{2}$-adrenoceptoragonists. Inhaled short-acting $\beta_{2^{-}}$ adrenoceptoragonists or, less frequently, anticholinergic drugs are used either on an as required basis, prophylactically, i.e. prior to exercise, or as rescue medication. Anti-inflammatory glucocorticoids are primarily long-term medications and are aimed at the treatment of airway inflammation and responsiveness [3]. In very selected cases, disodium cromoglycate and nedocromil are available as alternatives to treatment with very low doses of inhaled steroids. Because of their significant side-effects, systemic steroids are used exclusively for the treatment of severe asthma or asthma exacerbations against which other therapies exhibit insufficient effects.

\section{Bronchodilators}

$\beta_{2}$-Adrenoceptor agonists. For decades, $\beta_{2}$-adrenoceptor agonists have been among the most important drug classes for the treatment of bronchial asthma. In the meanwhile, short- and long-acting inhaled $\beta_{2}$-adrenoceptor agonists have become available. It is recommended that short-acting preparations (e.g. fenoterol, salbutamol and terbutaline) be used on an as needed basis, whereas the long-acting preparations (salmeterol and formoterol) should be used in combination with inhaled glucocorticoids within the framework of the long-term treatment. Both short- and long-acting preparations possess reliable bronchodilator effects. Moreover, there is some evidence that shortacting $\beta_{2}$-adrenoceptor agonists also exhibit antiinflammatory effects [4], although direct proof in vivo has been difficult to obtain. In this context, the effect of long-acting drugs in combination with steroids on the frequency of exacerbations might support an additional effect of this class of drug on airway inflammation $[5,6]$.

At present, clinical and experimental experience with short- and long-acting $\beta_{2}$-adrenoceptor agonists seems to suggest that it is rather unlikely that novel bronchodilators, in the foreseeable future, that are better tolerated and more effective, will be developed. Since $\beta_{2}$-adrenoceptor agonists are believed to cause airway smooth muscle to relax primarily by increasing intracellular levels of cyclic adenosine monophosphate and opening potassium channels, attempts have been made to imitate these effects with other substances, such as nonselective phosphodiesterase inhibitors and potassium channel openers. These drugs were shown to be far less effective as bronchodilators compared to $\beta$-adrenoceptor agonists, and their application at higher doses was limited by marked side-effects. Therefore, current drug research focuses primarily on the development of new substances that interfere with pathways of inflammation and those that might provide preventive approaches for the treatment of asthma.

Anticholinergics. Relaxation of airway smooth muscle can be effected by stimulation of the adrenergic nervous system through $\beta_{2}$-adrenoceptor agonists, on the one hand, and, on the other, by inhibition of the cholinergic nervous system by anticholinergic drugs. However, antagonists of muscarinic receptors, such as the short-acting ipratropium bromide, which nonselectively inhibit the effect of acetylcholine on muscarinic receptors, play only a minor role in the treatment of asthma. Ipratropium bromide is administered by inhalation and is primarily used as an "as-needed medication" in cases of intolerance of $\beta$-agonists. Since newly developed long-acting anticholinergics are primarily used in the treatment of chronic obstructive pulmonary disease $[7,8]$ they will not be discussed further here.

\section{Anti-inflammatory therapy}

Mediators such as prostanoids, histamine, leukotrienes, cytokines, chemokines and immunoglobulins are believed to play a central role in the pathogenesis and maintenance of airway inflammation in asthma. Their individual contributions, effects and origins are currently under intense investigation. Better understanding of these pathways could contribute to unravelling the mode of action of the currently used and effective classes of drugs (e.g. glucocorticoids) and might identify new targets for asthma therapy.

Anti-inflammatory or immunosuppressive therapy can intervene at the levels of synthesis, release and effects of inflammatory mediators. Conceptually, improved understanding of the regulatory mechanisms should lead to a more specific and hence more effective form of therapy. However, whether such specific approaches will lead to the expected effects in vivo must be evaluated in clinical studies. The development of such "tailor-made" interventions will 
be complicated by differences between species, since results from animal studies, in general, are only of limited predictive value in the clinical setting; this is even more evident from data from recent clinical trials, reviewed later.

Glucocorticoids. Glucocorticoids are the most effective anti-inflammatory drugs used in the treatment of asthma. Clinical studies have shown that steroids primarily affect the allergic late-phase reaction [9]. Although asthma can be controlled with high doses of systemic steroids (prednisone, prednisolone, methylprednisolone, fluocortolone and triamcinolone) in almost every patient, the use of systemic steroids over a longer period of time is limited by marked sideeffects.

Inhaled steroids (budesonide, beclometasone dipropionate (BDP), flunisolide and fluticasone), which in low doses have hardly any unwanted effects, although side-effects have been described at high doses, have been available since the early 1970s. Inhaled corticosteroids are currently the drugs of first choice in the long-term treatment of asthma, and are the only drugs for the treatment of this condition that have a documented effect on mortality [10].

The effect of glucocorticoids is mediated via a cytoplasmic glucocorticoid receptor. Bound to this receptor, steroids enter the nucleus, where they regulate gene transcription; synthesis of proinflammatory cytokines is increased and that of anti-inflammatory cytokines enhanced [11]. It has been speculated that the anti-inflammatory effects of steroids are mediated mainly by inactivation of transcription factors, whereas the unwanted effects result primarily from binding of steroids to deoxyribonucleic acid [12]. On this basis, drug development has been aimed at developing steroids with an improved ratio of desired to unwanted effects, e.g. transactivation/transrepression ratio. Whether this concept holds true in clinical practice remains to be evaluated.

Additionally, glucocorticoids with novel pharmacokinetic profiles are currently being tested [13]. Even modern inhaled glucocorticoids, such as fluticasone, with high lipophilicity, are absorbed via the lung after topical application and may, therefore, still exert sideeffects despite a high degree of first-pass metabolism $[13,14]$. Therefore, efforts are being made to develop steroids, which are metabolized locally in the lung or in the plasma and/or are not absorbed at mucous membranes, e.g. ciclesonide [15].

Furthermore, the increasing avoidance of chlorofluorocarbon (CFC)-containing products has led to the development of novel metered-dose inhalers. CFC-free hydroflouralkane-containing BDP was shown to have an improved deposition profile compared to CFC-BDP reaching the small airways [16]. This might have consequences for the dosage and the treatment of patients with inflammation of primarily the small airways.

\section{Cromones}

Although disodium cromoglycate and nedocromil have been used in the treatment of asthma for many years, their mode of action remains unknown. Clinical studies have shown that they exert almost no bronchodilatory effect, while reducing both the early and the late allergic response [9]. These drugs are safe and, in selected patients with mild asthma, might be used as an alternative anti-inflammatory therapy [17], although low doses of inhaled steroids are preferred at present.

\section{Methylxanthines}

Nonselective inhibitors of cyclic nucleotide phosphodiesterase, such as theophylline, have been used in the treatment of bronchial asthma for several decades [18] and are still included in current guidelines [1, 19].

Alongside a moderate bronchodilatory effect [20, 21], phosphodiesterase inhibitors have been shown to reduce airway inflammation [22, 23] and to be effective against early- and late-phase allergic responses. The mechanisms by which methylxanthines exert these effects appear to involve adenosine receptor antagonism [24-26] and, through elevation of intracellular cyclic adenosine monophosphate concentrations [27, 28], a direct relaxant effect on smooth muscle, as well as inhibition of mediator release from inflammatory cells [29].

Clinical studies have shown that the effect of theophylline on the early- and late-phase allergic response cannot be explained by its mild bronchodilatory effect $[20,30]$, which, if at all, can be demonstrated only in response to very high doses that are frequently accompanied by side-effects. It is more likely that the effects on allergic response that can be observed even after low doses of theophylline result from a direct effect on inflammatory cells $[22,31]$.

Use of theophylline is frequently limited by its sideeffects, which probably result from nonselective inhibition of phosphodiesterase isoenzymes. Therefore, in recent years, drug research has aimed at developing selective phosphodiesterase inhibitors with reduced side-effects.

\section{Leukotriene receptor antagonists and synthase inhibitors}

Leukotrienes and histamine are the most important mediators in allergic asthma [32], and are released after contact with allergen from mast cells, eosinophils and basophils. Although antihistamines have no proven and documented effect in asthma, "antileukotrienes" have been developed that inhibit either the synthesis of leukotrienes (5-lipoxygenase inhibitors) or the interaction of leukotrienes with their receptors. To date, three drugs from this class of anti-leukotrienes that have been approved for the combination with inhaled steroids in different parts of the world, the leukotriene receptor antagonists, montelukast, zafirlukast and pranlukast [33]. In clinical studies, montelukast was shown to reduce allergen- and exercise-induced bronchoconstriction. Other studies demonstrated that inhibition of the leukotriene 
pathway might decrease asthma symptoms, increase lung function and reduce the use of rescue medication [34]. However, only a certain subgroup of patients, including some patients with severe asthma, appear to respond to treatment with antileukotrienes. Although it has been indicated that patients with aspirininduced asthma might benefit from this treatment [35], it is, unfortunately, not possible to identify the subgroup in advance.

\section{Combination therapy}

Inhaled steroid preparations, alone or in combination with long-acting $\beta_{2}$-adrenoceptor agonists [36], form the basis of the long-term treatment of asthma. Dependent on asthma severity, this combination of drugs can be supplemented with the phosphodiesterase inhibitor, theophylline, not only because of its mild bronchodilating effects but also because of its suggested steroid-sparing effects [37].

\section{Combining glucocorticoids and $\beta_{2}$-adrenoceptor agonists}

Combination inhalers that contain a long-acting $\beta_{2}$-adrenoceptor agonist and an inhaled steroid, i.e. salmeterol/fluticasone-dipropionate $[36,38-40]$ and formoterol/budesonide $[6,41]$ have very recently been approved for the treatment of asthma and chronic obstructive pulmonary disease. The fixed combination is at least as effective as both of its components are individually and has the advantage that only one inhaler has to be used by the patient, which is expected, although not proven, to increase adherence to therapy [38]. Furthermore, it has been indicated that addition of a long-acting $\beta_{2}$-adreoceptor agonist to an inhaled steroid provides greater clinical advantage than doubling the dose of inhaled steroids in patients with symptomatic asthma $[36,42]$. The combination of both drugs in one inhaler influences neither the pharmacodynamic and pharmacokinetic characteristics nor the side-effect profiles of the individual substances [40].

\section{Combining glucocorticoids and theophylline}

Similar to findings with long-acting $\beta_{2}$-adrenoceptor agonists, theophylline can have a steroid-sparing effect, i.e. addition of theophylline might result in similar or even greater clinical benefit than doubling the dose of inhaled steroid [37, 43].

\section{Combining glucocorticoids and antileukotrienes}

Like long-acting $\beta_{2}$-adrenoceptor agonists and theophylline, leukotriene receptor antagonists have been demonstrated in a recently published clinical trial, to have a steroid-sparing effect. Addition of the leukotriene receptor agonist montelukast to the current treatment reduced the need for inhaled corticosteroids among patients requiring moderate-to-high doses of corticosteroid to maintain asthma control [44].

\section{Clinical approach}

According to guidelines, asthma severity can be classified as intermittent, mild persistent, moderate persistent or severe persistent based on a standardized assessment of asthma symptoms and lung function in combination with the current medication [1, 17, 45]. Although these classification criteria were published in 1995, the categories are still valid and are likely to be retained in the next Global Initiative for Asthma guidelines, which will be published in the near future. The clinical classification of asthma severity forms the basis of the stepwise approach to asthma pharmacotherapy. However, in addition to and regardless of the severity or "step", an important goal should always be the avoidance or control of asthma triggers. The "step" approach is represented in table 1.

In general, asthma medication can be divided into two groups: 1) controllers, such as corticosteroids, that are taken daily on a long-term basis to get and keep persistent asthma under control; and 2) relievers, e.g. $\beta_{2}$-adrenoceptor agonists, that act quickly to relieve bronchoconstriction and its accompanying acute symptoms such as cough, chest tightness and wheezing, and which can also be used on an as needed basis, i.e. as rescue medication.

In the treatment of patients with intermittent asthma (Step 1), short-acting $\beta_{2}$-adrenoceptor agonists should be used on an as needed basis to relieve symptoms and to prevent those which are provoked by exercise or exposure to allergens. If control is not achieved and symptoms require use of $\beta_{2}$-adrenoceptor agonists more than once a week, a stepping up should be considered.

Patients with mild persistent asthma (Step 2) should, in the first instance, be treated daily with inhaled steroids, 200-500 $\mu \mathrm{g}$, or, alternatively, with cromones (see earlier comments) or sustained-release theophylline. For the relief of acute symptoms, inhaled $\beta_{2}$-adrenoceptor agonists should be used at levels not exceeding three or four applications in a day. If the asthma is insufficiently controlled, the dose of the inhaled steroid can be increased (up to $800 \mu \mathrm{g}$ ) and/or a long-acting $\beta_{2}$-adrenoceptor agonist added, especially for persistent night-time symptoms.

Treatment of moderate persistent asthma (Step 3) involves inhaled corticosteroids at 800-2,000 $\mu \mathrm{g}$ and the use of long-acting $\beta_{2}$-adrenoceptor agonists. Especially for night-time symptoms, sustained-release theophylline or long-acting oral $\beta_{2}$-adrenoceptor agonists can be added, and for the treatment of acute symptoms, short-acting bronchodilators should be used as needed up to three or four times a day. The addition of a long-acting $\beta_{2}$-adrenoceptor agonist or low-dose theophylline might have the same or even a better effect than doubling the dose of inhaled steroid. Treatment with an antileukotriene can be a further option.

Patients with severe persistent asthma (Step 4) should be treated with inhaled corticosteroids at $\geqslant 800-2,000 \mu \mathrm{g}$ and long-acting $\beta_{2}$-adrenoceptor agonists and/or sustained-release theophylline as well as long-term oral corticosteroids. Short-acting $\beta_{2}$-adrenoceptor agonists should be used for the relief of symptoms. During exacerbations, an oral 
Table 1. - Summary of the stepwise approach to asthma therapy*

\begin{tabular}{|c|c|c|c|c|}
\hline & \multicolumn{4}{|c|}{ Step and asthma severity } \\
\hline & 1: intermittent & 2: mild persistent & 3: moderate persistent & 4: severe persistent \\
\hline $\begin{array}{l}\text { Clinical } \\
\text { features } \\
\text { before } \\
\text { treatment }\end{array}$ & $\begin{array}{l}\text { Intermittent } \\
\text { symptoms } \\
<1 \cdot \text { week }^{-1} \\
\text { Night-time } \\
\text { symptoms } \\
<2 \cdot \text { month }^{-1} \\
\text { Brief } \\
\text { exacerbations } \\
\text { (hours to days) } \\
\text { Asymptomatic } \\
\text { and normal } \\
\text { lung function } \\
\text { between } \\
\text { exacerbations } \\
\text { PEF or FEV } 1 \\
>80 \% \text { pred; } \\
\text { variability }<20 \%\end{array}$ & $\begin{array}{l}\text { Symptoms }>1 \cdot \text { week }^{-1} \\
\text { but }<1 \cdot \text { day }^{-1} \\
\text { Exacerbations } \\
\text { may affect } \\
\text { activity } \\
\text { and sleep } \\
\text { Night-time } \\
\text { symptoms } \\
>2 \cdot \text { month }^{-1} \\
\text { PEF or FEV } 1 \\
\geqslant 80 \% \text { pred; } \\
\text { variability } \\
<20-30 \%\end{array}$ & $\begin{array}{l}\text { Symptoms daily } \\
\text { Exacerbations } \\
\text { affect activity } \\
\text { and sleep } \\
\text { Night-time } \\
\text { symptoms } \\
>1 \cdot \text { week }^{-1} \\
\text { Daily use } \\
\text { of inhaled } \\
\text { short-acting } \\
\beta_{2} \text {-agonist } \\
\text { PEF or FEV1 }>60- \\
<80 \% \text { pred; } \\
\text { variability }>30 \%\end{array}$ & $\begin{array}{l}\text { Continuous } \\
\text { symptoms } \\
\text { Frequent } \\
\text { exacerbations } \\
\text { Frequent } \\
\text { night-time } \\
\text { symptoms } \\
\text { Physical } \\
\text { activities limited } \\
\text { by symptoms } \\
\text { PEF or FEV1 } \\
<60 \% \text { pred; } \\
\text { variability }>30 \%\end{array}$ \\
\hline $\begin{array}{l}\text { Controller } \\
\text { treatment }\end{array}$ & & $\begin{array}{l}\text { Low dose } \\
\text { inhaled steroid } \\
(400 \mu \mathrm{g})\end{array}$ & $\begin{array}{l}\text { Conventional approach } \\
\text { High-dose } \\
\text { inhaled steroid } \\
\text { (doubling of low } \\
\text { dose up to } 2 \mathrm{mg} \text { ) } \\
\text { New approach } \\
\text { Low-dose } \\
\text { inhaled steroid } \\
\text { plus long-acting inhaled } \\
\beta_{2} \text {-agonist } \\
\text { (salmeterol or formoterol, } \\
\text { also in fixed } \\
\text { combination), } \\
\text { plus low dose } \\
\text { theophyline or plus } \\
\text { anti-leukotriene } \\
\text { (montelukast, } \\
\text { zafirlucast) }\end{array}$ & $\begin{array}{l}\text { High-dose inhaled } \\
\text { steroids }(0.8-2 \mathrm{mg}) \\
\text { Oral corticosteroid } \\
\text { long-term } \\
\text { plus long-acting } \\
\text { bronchodilator } \\
\text { (long-acting } \\
\beta_{2} \text {-agonist } \\
\text { and/or } \\
\text { theophylline) } \\
\text { Additional } \\
\text { bronchodilators } \\
\text { Anticholinergics } \\
\text { Oral } \beta_{2} \text {-agonists } \\
\text { Nebulizers }\end{array}$ \\
\hline $\begin{array}{l}\text { Reliever } \\
\text { treatment }\end{array}$ & $\begin{array}{l}\text { Inhaled } \beta_{2} \text {-agonist } \\
\quad<1 \text { dose }^{-w_{e e k}}{ }^{-1}\end{array}$ & $\begin{array}{l}\text { Inhaled } \beta_{2} \text {-agonist } \\
\quad<3-4 \text { doses }^{\prime} \text { week }^{-1}\end{array}$ & $\begin{array}{l}\text { Inhaled } \beta_{2} \text {-agonist } \\
\quad<3-4 \text { doses }^{-} \text {week }^{-1}\end{array}$ & $\begin{array}{l}\text { Inhaled } \beta_{2} \text {-agonist } \\
\text { as needed } \\
\text { for symptoms }\end{array}$ \\
\hline
\end{tabular}

\footnotetext{
*: according to current guidelines [1]; Note the treatment choices at Step 3. It has recently been shown that the addition of long-acting $\beta_{2}$-adrenoceptor agonists, low-dose theophylline or antileukotrienes is equally or even more effective than doubling the dose of inhaled steroid. (Adapted from [1]).
}

corticosteroid may be needed at any time and at any step. If control is sustained at any of the four steps for $\geqslant 3$ months, the possibility of a gradual stepwise reduction in treatment should be evaluated.

\section{Treatment options}

The established therapeutic strategies, as recommended by current guidelines and based on an understanding of the pathophysiological and immunological mechanisms of asthma have been discussed above. There are many more approaches and new developments such as specific immunotherapy and cytokine, chemokine or adhesion molecule agonists/ antagonists as well as monoclonal antibodies, which are partly reviewed in other articles in this supplement. Treatment choices differ between countries and must take into account the convenience to the patient and the occurrence of side-effects. Additionally, the cost of the therapy and reimbursement policies also influence therapeutic strategies.

It appears, however, despite all the effort put into developing new strategies for the treatment of asthma, established drug entities such as $\beta_{2}$-adrenoceptor agonists with a long duration of action and inhaled corticosteroids remain the first-line therapy recommended by current guidelines. In general, today's combinations of drugs that primarily relieve airway smooth muscle tone with those having a controller effect on airway inflammation will remain tomorrow's treatment for the foreseeable future.

\section{References}

1. Global Initiative for Asthma. Global Strategy for Asthma Management and Prevention. NHLBI/WHO Workshop report. Publication No. 95-3659. 1995. 
2. Rabe KF, Vermeire PA, Soriano JB, Maier WC. Clinical management of asthma in 1999: the Asthma Insights and Reality in Europe (AIRE) study. Eur Respir J 2000; 16: 802-807.

3. Sont JK. How do we monitor asthma control? Allergy 1999; 54: 68-73.

4. Butchers PR, Varday CJ, Johnson M. Salmeterol: a potent and long-acting inhibitor of inflammatory mediator release from human lung. Br J Pharmacol 1991; 104: 672-676.

5. Pauwels RA, Lofdahl CG, Postma DS, et al. Effect of inhaled formoterol and budesonide on exacerbations of asthma. Formoterol and Corticosteroids Establishing Therapy (FACET) International Study Group. $N$ Engl J Med 1997; 337: 1405-1411.

6. Kips JC, $\mathrm{O}^{\prime}$ Connor BJ, Inman MD, Svensson K, Pauwels RA, O'Byrne PM. A long-term study of the antiinflammatory effect of low-dose budesonide plus formoterol versus high-dose budesonide in asthma. Am J Respir Crit Care Med 2000; 161: 996-1001.

7. Pauwels RA, Buist AS, Calverley PM, Jenkins CR, Hurd SS. Global strategy for the diagnosis, management, and prevention of chronic obstructive pulmonary disease. NHLBI/WHO Global Initiative for Chronic Obstructive Lung Disease (GOLD) Workshop summary. Am J Respir Crit Care Med 2001; 163: $1256-1276$

8. Disse B. Antimuscarinic treatment for lung diseases: from research to clinical practice. Life Sci 2001; 68: 2557-2564.

9. Cockcroft DW, Murdock KY. Comparative effects of inhaled salbutamol, sodium cromoglycate, and beclomethasone dipropionate on allergen-induced early asthmatic responses, late asthmatic responses, and increased bronchial responsiveness to histamine. J Allergy Clin Immunol 1987; 79: 734-740.

10. Suissa S, Ernst P, Benayoun S, Baltzan M, Cai B. Low-dose inhaled corticosteroids and the prevention of death from asthma. N Engl J Med 2000; 343: 332336.

11. Barnes PJ, Adcock IM. NF-kB: a pivotal role in asthma and a new target for therapy. Trends Pharmacol Sci 1997; 18: 46-50.

12. Vayssiere BM, Dupont S, Choquart A, et al. Synthetic glucocorticoids that dissociate transactivation and AP-1 transrepression exhibit antiinflammatory activity in vivo. Mol Endocrinol 1997; 11: 1245-1255.

13. Barnes PJ, Pedersen S, Busse WW. Efficacy and safety of inhaled corticosteroids. New developments. Am J Respir Crit Care Med 1998; 157: S1-S3.

14. Lipworth BJ, Jackson CM. Safety of inhaled and intranasal corticosteroids: lessons for the new millennium. Drug Saf 2000; 23: 11-33.

15. Taylor DA, Jensen MW, Kanabar V, et al. A dosedependent effect of the novel inhaled corticosteroid ciclesonide on airway responsiveness to adenosine-5'monophosphate in asthmatic patients. Am J Respir Crit Care Med 1999; 160: 237-243.

16. Leach CL, Davidson PJ, Boudreau RJ. Improved airway targeting with the CFC-free HFA-beclomethasone metered-dose inhaler compared with CFCbeclomethasone. Eur Respir J 1998; 12: 1346-1353.

17. Wettengel R, Berdel D, Hofmann D, et al. Asthmatherapie bei Kindern und Erwachsenen. Empfehlungen der Deutschen Atemwegsliga in der Deutschen Gesellschaft für Pneumologie. Med Klin 1998; 93: 639-650.
18. Weinberger M, Hendeles L. Theophylline in asthma. $N$ Engl J Med 1996; 334: 1380-1388.

19. Guidelines for the Diagnosis and Management of Asthma. Expert Panel Report 2. Publication No. 1997 97-4051. 1997.

20. Pauwels R, van Renterghem D, Van der Straeten M, Johannesson N, Persson CGA. The effect of theophylline and enprofylline on allergen-induced bronchoconstriction. J Allergy Clin Immunol 1985; 76: 583-590.

21. Ward AJ, McKenniff M, Evans JM, Page CP, Costello JF. Theophylline: an immunomodulatory role in asthma. Am Rev Respir Dis 1993; 147: 518-523.

22. Banner KH, Page CP. Anti-inflammatory effects of theophylline and selective phosphodiesterase inhibitors. Clin Exp Allergy 1996; 26: 2-9.

23. Karlsson J-A. Theophylline: anti-inflammatory effects. In: Leff AR, editor. Pulmonary and Critical Care Pharmacology and Therapeutics. USA, McGraw-Hill, 1996; pp. 609-620.

24. Crimi N, Polosa R, Mistretta A. Role of adenosine in the pathogenesis of bronchial asthma. Recenti Prog Med 1989; 80: 372-376.

25. Karlsson J-A. Purines and sensory neuropeptides in human asthma. Bull Eur Physiopathol Respir 1987; 23: 95s-101s.

26. Coward W, Sagara H, Church MK. Asthma, adenosine, mast cells and theophylline. Clin Exp Allergy 1998; 28: 42-46.

27. Bergstrand H. Phosphodiesterase inhibition and theophylline. Eur J Respir Dis 1980; 109: 37-44.

28. Hill GE, Anderson JL, Whitten CW. Ketamine inhibits agonist-induced cAMP accumulation increase in human airway smooth muscle cells. Can J Anaesth 1999; 46: 1172-1177.

29. Louis R, Bury T, Corhay JL, Radermecker M. LY18665, a phosphodiesterase inhibitor, inhibits histamine release from human basophils, lung and skin fragments. Int J Immunopharmacol 1992; 14: 191-194.

30. Ward JK, Belvisi MG, Fox AJ, et al. Modulation of cholinergic bronchoconstrictor responses by endogenous nitric oxide and vasoactive intestinal peptide in human airways in vitro. J Clin Invest 1993; 92 736-742.

31. Karlsson J-A. Anti-inflammatory effects of phosphodiesterase inhibitors. In: Leff AR, ed. Pulmonary and Critical Care Pharmacology and Therapeutics. USA, McGraw-Hill, 1996; pp. 621-633.

32. Roquet A, Dahlen B, Kumlin M, et al. Combined antagonism of leukotrienes and histamine produces predominant inhibition of allergen-induced early and late phase airway obstruction in asthmatics. Am J Respir Crit Care Med 1997; 155: 1856-1863.

33. Markham A, Faulds D. Montelukast. Drugs 1998; 56: 251-256.

34. Drazen JM, Israel E, O'Byrne PM. Treatment of asthma with drugs modifying the leukotriene pathway. N Engl J Med 1999; 340: 197-206.

35. Dahlen B, Nizankowska E, Szczeklik A, et al. Benefits from adding the 5-lipoxygenase inhibitor zileuton to conventional therapy in aspirin-intolerant asthmatics. Am J Respir Crit Care Med 1998; 157: 1187-1194.

36. Shrewsbury S, Pyke S, Britton M. Meta-analysis of increased dose of inhaled steroid or addition of salmeterol in symptomatic asthma (MIASMA). BMJ 2000; 320: 1368-1373.

37. Ukena D, Harnest U, Sakalauskas R, et al. Comparison of addition of theophylline to inhaled steroid with 
doubling of the dose of inhaled steroid in asthma. Eur Respir J 1997; 10: 2754-2760.

38. Bateman ED, Britton M, Carillo T, Almeida J, Wixon C. Salmeterol/fluticasone combination inhaler. A new, effective and well tolerated treatment for asthma. Clin Drug Invest 1998; 16: 193-201.

39. Chapman KR, Ringdal N, Backer V, Palmqvist M, Saarelainen S, Briggs M. Salmeterol and fluticasone propionate $(50 / 250 \mu \mathrm{g})$ administered via combination Diskus inhaler: as effective as when given via separate Diskus inhalers. Can Respir J 1999; 6: 45-51.

40. Spencer CM, Jarvis B. Salmeterol/fluticasone propionate combination. Drugs 1999; 57: 933-940.

41. McGavin JK, Goa KL, Jarvis B. Inhaled budesonide/ formoterol combination. Drugs 2001; 61: 71-78.

42. van Noord JA, Schreurs AJ, Mol SJ, Mulder PG.
Addition of salmeterol versus doubling the dose of fluticasone propionate in patients with mild to moderate asthma. Thorax 1999; 54: 207-212.

43. Evans DJ, Taylor DA, Zetterström O, Chung KF, $\mathrm{O}^{\prime}$ Conner BJ, Barnes PJ. A comparison of low-dose inhaled budesonide plus theophylline and high-dose inhaled budesonide for moderate asthma. $N$ Engl J Med 1997; 337: 1412-1418.

44. Lofdahl CG, Reiss TF, Leff JA, et al. Randomised, placebo controlled trial of effect of a leukotriene receptor antagonist, montelukast, on tapering inhaled corticosteroids in asthmatic patients. BMJ 1999; 319 : 87-90.

45. Britisch Thoracic Society. BTS guidelines for the management of chronic obstructive pulmonary disease. Thorax 1997; 52: S1-S28. 